\title{
The Japanese plasma cell dyscrasia syndrome: case report and theory of pathogenesis
}

\author{
MARTIN J. TOBIN* \\ M.B., M.R.C.P.I.
}

MUIRIS X. FITZGERALD

M.D., F.R.C.P.I., F.R.C.P.

Medical Professorial Unit, University College Dublin, St. Vincent's Hospital,
Elm Park, Dublin 4, Ireland

\begin{abstract}
Summary
A 54-year-old man developed pigmentation, clubbing, weight loss, oedema, hepatomegaly, lymphadenopathy, cold intolerance, hypotonia and hyporeflexia. Dominant laboratory findings were increased marrow plasma cells with IgA lambda paraproteinaemia, hypothyroidism, hyperprolactinaemia, hyperoestrogenaemia and biopsy-proven peripheral neuropathy. The clinical features and dramatic response to corticosteroids are consistent with the syndrome of plasma cell dyscrasia, polyneuropathy and endocrinopathy found predominantly in Japan. In our patient, immunofluorescence of neural tissues revealed paraprotein deposition. Although the pathogenesis is unknown, these multisystemic features may result from antibody activity or tissue deposition of paraprotein. Furthermore, the endocrinopathy may be localized at the hypothalamic level.
\end{abstract}

\section{Introduction}

The combination of plasma cell dyscrasia, polyneuropathy and endocrinopathy was first reported by Shimpo in 1968, and since then, over thirty cases have been reported from Japan (Takatsuki et al., 1977). Recently, non-Japanese patients with this syndrome have been described in the American (Trentham, Masi and Marker, 1976; Meshinpour, Myung and Kramer, 1977; Bardwick et al., 1980) and the European literature (Amiel, Machover and Droz, 1975; Lievre, 1977; Moya-Mir et al., 1980), but none has been reported from the British Isles. In this rare syndrome of unknown aetiology, a variety of clinical features have been described, including polyneuropathy, pigmentation, skin thickening, hyperhidrosis, oedema, hepatosplenomegaly, lymphadenopathy, sclerotic bone lesions, hypogonadism, hirsuitism,

\footnotetext{
*Present address: Mount Sinai Medical Center, 4300 Alton Road, Miami Beach, Florida 33140. Reprint requests to Professor M. X. Fitzgerald.
}

gynaecomastia, diabetes mellitus, hypothyroidism and fever.

The following case, the sixth described in a caucasian, displays some features not previously described. We propose a theory to explain the occurrence of polyneuropathy and endocrine disturbance in this syndrome.

\section{Case report}

A 64-year-old man was admitted to St Vincent's Hospital, Dublin, in February 1975. His presenting complaints were muscle weakness, weight loss of 7 $\mathrm{kg}$, ankle swelling and cold intolerance.

Five months previously, he was admitted to another hospital, with weakness, headache and weight loss. At that time, he was found to have digital clubbing, hepatomegaly, cervical lymphadenopathy and basal crepitations. Investigations showed a normal full blood count, urea and electrolytes, protein and liver function tests. Biopsies of a cervical node and liver showed non-specific changes. He was discharged on no treatment.

On this admission in addition to the above findings, he was noted to be markedly pigmented. Gynaecomastia, cachexia and pedal oedema were also evident. On neurological examination there was hypotonia, muscle weakness and reduced tendon jerks. The blood pressure was $140 / 90 \mathrm{mmHg}$.

Investigations revealed anaemia $(10.6 \mathrm{~g} / \mathrm{dl})$ with low serum iron, folic acid, and vitamin $B_{12}$. Leucocyte and platelet counts were normal. The erythrocyte sedimentation rate was markedly elevated at 106 $\mathrm{mm} / \mathrm{hr}$. Plasma cells constituted $10-20 \%$ of nucleated cells of a hypercellular marrow. Many of the plasma cells were present in syncytiae and showed bizarre morphological forms. A small proportion were flame cells.

Immunoelectrophoresis of the serum showed a paraprotein in the fast gamma region, IgA lambda in type. Serum IgA was elevated at $1092 \mathrm{mg} / \mathrm{dl}$ (normal 
$120-400 \mathrm{mg} / \mathrm{dl}$ ) with normal levels of IgG and IgM. IgA lambda light chains were found in the urine (12.3 $\mathrm{g} /$ litre). A lymph node biopsy was normal, and negative results were found for the following; rheumatoid factor, antinuclear factor, and antibodies against mitochondria, parietal cells, thyroid colloid and thyroid microsomes.

Initial endocrinological investigations indicated hypothyroidism. The serum thyroxine was $4.0 \mu \mathrm{g} / \mathrm{dl}$ (normal $5-13.7 \mu \mathrm{g} / \mathrm{dl}$ ), free thyroxine index 4.21 (normal 4.4-15.7), thyroid stimulating hormone 7.9 $\mu \mathrm{U} / \mathrm{ml}$ (normal $<5.5 \mu \mathrm{U} / \mathrm{ml}$ ). He also had a low normal basal 9.00 a.m. cortisol of $17 \mu \mathrm{g} / \mathrm{dl}$.

Neurological investigations revealed a gross reduction in motor conduction velocity and a sensorimotor peripheral neuropathy on electromyography. Muscle biopsy showed a mixed denervation atrophy and myopathy, consistent with carcinomatous neuromyopathy. A Schilling test excluded pernicious anaemia. The neuropathy showed no response to hydroxocobalamin therapy.

Chest X-ray showed interstitial oedema and small pleural effusions, which were shown to be exudative. Barium meal and small bowel follow-through, faecal fat estimations, a liver-spleen scan and biopsies of the liver and rectum were non-contributory. A skeletal $\mathrm{X}$-ray survey showed no evidence of osteosclerotic bone lesions.

While investigations were being carried out, the patient's condition deteriorated; he became bedbound, with bilateral foot drop; he lost $17 \mathrm{~kg}$ in weight, and he became obtunded. Steroid therapy was commenced and this was followed by an immediate dramatic improvement. His oedema, hepatomegaly and lymphadenopathy rapidly regressed. There was a marked improvement in his neuropathy, and he became mobile. Over the following year his weight rose from 33 to $58 \mathrm{~kg}$ on prednisolone $20 \mathrm{mg}$ daily.

In June 1976 he was readmitted for re-evaluation. His serum IgA had dropped to $606 \mathrm{mg} / \mathrm{dl}$ and bone marrow examination showed a normal plasma cell population. Thyroid function tests had returned to normal except for an absent response to thyroid releasing hormone. Urinary oestrogens were slightly raised, and a glucose tolerance test was normal. The haemoglobin and erythrocyte sedimentation rate were also now normal.

In March 1977 he was readmitted with a tender erythematous nodular swelling on his right achilles tendon. An excision biopsy showed fat necrosis. Six months later he was readmitted because of gangrene of his right foot due to severe atheromatous disease.

In February 1979 he developed gangrene of his left leg, and an above knee amputation was performed. Sural nerve biopsy showed moderate demyelination. Single teased fibres showed varying degrees of
Wallerian degeneration. Immunofluorescence, performed by the immunoperoxidase method, showed moderate IgA deposition, with absent IgG and IgM. There was no evidence of vasculitis. While in the hospital, further studies showed a raised serum prolactin $(43 \mathrm{ng} / \mathrm{ml}$; normal $1-11 \mathrm{ng} / \mathrm{ml})$ and oestradiol $(55 \mathrm{pg} / \mathrm{ml}$; normal $15-40)$ with reduced testosterone $(1.57 \mathrm{ng} / \mathrm{ml}$; normal $2.5-10 \mathrm{ng} / \mathrm{ml})$. No serum paraprotein or urinary light chains were detected.

He died in May 1979 from bronchopneumonia. Permission for a post-mortem was refused.

\section{Discussion}

The plasma cell dyscrasia syndrome has become a well-recognized entity in Japan, being observed in 32 patients (Takatsuki et al., 1977). Outside Japan, four cases have been reported from the United States (Trentham et al., 1976; Meshinpour et al., 1977; Bardwick et al., 1980) and another three cases from Europe (Amiel et al., 1975; Lievre, 1977; Moya-Mir, 1980). This present case is the sixth in a caucasian, and as in previous reports the patient exhibited the classic triad of plasma cell dyscrasia, polyneuropathy and endocrinopathy; additionally, the patient was found to have paraprotein deposition, a feature not previously described.

A plasma cell dyscrasia was clearly present, with an increase in the marrow plasma cell population, and the presence of an $\operatorname{IgA}$ lambda $M$ band in the serum, and lambda light chains in the urine. While these lambda chains are important as diagnostic markers, they may also be of pathogenetic signifcance, as in multiple myeloma, where they may be deposited in the skin, or form amyloid fibrils (Cohen and Cathcart, 1974; Linke et al., 1973). Furthermore, the antibody activity recently demonstrated in some paraproteins (Seligman and Brouet, 1973; Osterland and Espinoza, 1975) might be a factor in producing organ damage. It is of interest that no patient with the Japanese plasma cell dyscrasia syndrome has had a kappa light chain paraprotein, in contrast to uncomplicated multiple myeloma where both chain types are found.

Peripheral neuropathy, causing bilateral foot-drop, immobilized our patient, and its severity was further reflected by gross reduction in nerve conduction velocity and histological evidence of Wallerian degeneration and denervation atrophy of muscle. While a similar neuropathy occurs occasionally in classic myeloma, no endocrine disturbance has been reported in this condition (Drieger and Pruzanski, 1980). The cause of the neuropathy in myeloma and in the plasma cell dyscrasia syndrome is unknown; it may be related to an antibody activity of paraproteins directed against neural tissue (Latov et al., 1980 ), or alternatively, paraprotein deposition in 
peripheral nerve as observed in our patient. While we found immunoglobulin deposition in peripheral nerve, tests to determine if it was monoclonal in origin were not performed.

Endocrinopathy is the third cardinal feature of the syndrome, and a variety of disturbances have been described: hypothyroidism, hypogonadism, gynaecomastia, and diabetes mellitus. Our patient, like the cases of Trentham et al. (1976) and Imawari et al. (1974) and one of the patients of Bardwick et al. (1980) had a reduced serum total thyroxine and free thyroxine index, and a marginally elevated thyroidstimulating hormone (TSH) level. The absence of thyroid antibodies and only a slight increase in TSH suggests tertiary (i.e. hypothalamic) rather than secondary hypothyroidism, because in the latter condition the TSH levels are undetectable, while in primary hypothyroidism, the levels are usually greater than $100 \mu \mathrm{U} / \mathrm{ml}$ (Patel and Burger, 1973). The presence of a low serum thyroxine despite an elevated TSH level in patients with hypothalamic hypothyroidism suggests that TSH 'leaking' from an unstimulated pituitary is not biologically active, although it cross-reacts immunologically with normal TSH, giving an elevated TSH level on immunoassay. The presence of thyrotropin releasing hormone (TRH) may be necessary, not only to augment the release of TSH, but also to produce TSH of full biological activity. Patients with hypothalamic hypothyroidism typically display an exaggerated TSH response to TRH administration (Falia et al., 1973). The flat response observed in our patient may have been due to the known damping action of high-dose corticosteroid on TSH response (Otsuki, Dakoda and Baba, 1973).

The other endocrine disturbances observed in our patient were impotence and gynaecomastia. The elevated prolactin level may have been responsible for both of these features, together with the reduced testosterone level (Franks et al., 1978). Hyperprolactinaemia was also present in both patients of Bardwick et al. (1980) and it may prove to be a constant endocrinological feature of this syndrome. When one of these patients was treated with bromoergocryptine, the prolactin levels fell but the gonadal hormone levels remained unchanged. Later during the course of our patient's illness, the plasma oestradiol level rose above the normal range. Imawari et al. (1974) also noted an increased oestradiol level in their patient, but the cause of this abnormality is unknown.

The varying endocrine disturbances observed in our patient are best explained on a hypothalamic basis. The pattern of thyroid function tests, together with hyperprolactinaemia and the slightly reduced plasma cortisol is consistent with this hypothesis. Furthermore, functional and histological studies in previous reports have failed to show any abnormality in the gonads, adrenals or thyroid gland. The postulated hypothalamic damage could be mediated either by lambda chain deposition, or by paraproteins possessing antibody activity directed towards hypothalamic tissues. Unfortunately, an autopsy was not permitted and so we were unable to examine the hypothalamus.

Generalized oedema, pleural effusions and/or ascites are common findings in patients with this syndrome (Takasuki et al., 1977; Imawari et al., 1974; Trentham et al., 1976). While our patient had severe cardiovascular disease which could explain his peripheral and pulmonary oedema, it was unlikely to be the cause of his pleural effusions, which were exudative in type. Neither can the fluid retention be explained by hypoproteinaemia or renal failure. It is unlikely that the oedema and effusions resulted from non-specific protein leakage secondary to increased capillary permeability as suggested by Trentham $e t$ al. (1976).

While the features of this rare syndrome are varied and appear to be unrelated, it is clear from the above discussion that their pathogenesis probably has a common immunological basis, with tissue damage resulting from the antibody action of paraproteins or deposition of lambda chains. An immunological basis to this syndrome is supported by the dramatic 8 effect of steroids on the oedema, lymphadenopathy, neuropathy, abnormal thyroid function tests and theo number of marrow plasma cells, and furthermore, by? reports of relapse on discontinuation of therapy (Trentham et al., 1976).

Although this emerging syndrome was initially confined to the Eastern hemisphere, it obviously occurs in Europe and North America. Its recognition is important because its behaviour differs from that of uncomplicated multiple myeloma, and also because it may respond to steroid therapy.

\section{Acknowledgments}

We are grateful to Drs T. J. McKenna, J. Dinn, H. McLaughlin, J. Greally, R. Towers, L. O'Connell and M. Hutchinson for help and advice and to Mrs N. Martin and Mr P. Seko for technical assistance.

\section{References}

Amiel, J.L., Machover, D. \& DROZ, J.P. (1975) Dyscrasie plasmacytaire avec arteriopathie, polyneuropathie, syndrome endocrinier. Annales de Médecine Interne, 126, 745.

Bardwick, P.A., Zvaifler, N.J., Gill, G.N., Newman, D., Greenway, G.D. \& ReSNiCK, D.L. (1980) Plasma cell dyscrasia with polyneuropathy, organomegaly, endocrinopathy, M Protein and skin changes: The POEMS syndrome. Medicine (Baltimore), 59, 311 .

COHEN, A.S. \& CATHCART, E.S. (1974) Amyloidosis and immunoglobulins. Advances in Internal Medicine, 19, 41.

Driedger, H. \& Pruzanski, W. (1980) Plasma cell neoplasia and peripheral polyneuropathy. Medicine (Baltimore), 59, 301. 
Faglia, G., Beck-Pecoz, P., Ferrari, C., Ambrosi, B., Spada, A., Travaglini, P. \& Paracchi, S. (1973) Plasma thyrotropin response to thyrotropin-releasing hormone in patients with pituitary and hypothalamic disorders. Journal of Clinical Endocrinology and Metabolism, 37, 595.

Franks, S., Jacob, H.S., Martin, N. \& NabarRo, J.D.N. (1978) Hyperprolactinemia and impotence. Clinical Endocrinology, 8, 277.

Imawari, M., Akatsuka, N., Ishibashi, M., Beppu, H., Suzuki, H. \& YoshitoshI, Y. (1974) Syndrome of plasma cell dyscrasia, polyneuropathy, and endocrine disturbance. Annals of Internal Medicine, 81, 490.

latov, N., Sherman, W.H., Nemni, R., Galassi, G., Shyong, J.S., Penn, A.S., Chess, L., Olarte, M.R., Rowland, L.P. \& Osserman, E.F. (1980) Plasma-cell dyscrasia and peripheral neuropathy with a monoclonal antibody to peripheral-nerve myelin. New England Journal of Medicine, 303, 618.

LIEVRE, J.A. (1977) Plasma cell dyscrasia with polyneuropathy, endocrine disorders and nodular osteocondensation resembling osteopoikilosis. Revue du Rhumatisme, 44, 281.

LINKE, R.P., TISCHENDORF, F.W., ZUCKER-FrankLIN, D. \& FRANKLIN, E.C. (1973) The formation of amyloid-like fibrils in vitro from .Bence Jones proteins of $\mathrm{V}$ I subclass. Journal of Immunology, 111, 24.

MeshinPour, H., MyUng, C.G. \& KRAMER, L.S. (1977) A unique multisystemic syndrome of unknown origin. Archives of Internal Medicine, 137, 1719.
Moya-Mir, M.S., Barbadillo, R., MarTin-Jimenez, T., MartinMarTin, F., Cuervas-Mons, V., Sanchez-Miro, I. \& GarcioMerino, J.A. (1980) Plasma cell dyscrasia with polyneuritis and dermato-endocrine alterations. Review of a new case outside Japan. Postgraduate Medical Journal, 56, 427.

OSTERLAND, C.K. \& EsPINOZA, L.R. (1975) Biological properties of myeloma proteins. Archives of Internal Medicine, 135, 32.

OTSUKı, M., DAKODA, M. \& BABA, S. (1973) Influence of glucocorticoids on TRF-induced TSH response in man. Journal of Clinical Endocrinology and Metabolism, 36, 95.

PATEL, Y.C. \& BURGER, H.G. (1973) Serum thyrotropin (TSH) in pituitary and/or hypothalamic hypothyroidism: normal or elevated basal levels and paradoxical responses to thyrotropinreleasing hormone. Journal of Clinical Endocrinology and Metabolism, 37, 190.

Seligman, M. \& Brouet, J.C. (1973) Antibody activity of human myeloma globulins. Seminars in Hematology, 10, 163.

SHIMPO, S. (1968) Solitary plasmacytoma with polyneuritis and endocrine disturbances. Nippon Rinsho, 26, 2444.

Takatsuki, K., Uchiya, T., Sagawa, K. \& Yodol, J. (1970) Plasma cell dyscrasia with polyneuropathy and endocrine disorder: A review of 32 patients. Topics in Hematology (Ed. by Seno, S., Takaku, F. \& Irino, S.), p. 454. Excerpta Medica, Amsterdam. Trentham, D.E., MASI, A.T. \& MARKER, H.W. (1976) Polyneuropathy and anasarca: evidence for a new connective-tissue syndrome and vasculopathic contribution. Annals of Internal Medicine, 84, 271. 